\title{
ERRATUM
}

\section{Practice Scripts and Descriptions}

D. McCown et al., Teaching Mindfulness: A Practical Guide for Clinicians and Educators, DOI 10.1007/978-0-387-09484-7, pp. 193-220,

(C) Springer Science+Business Media, LLC 2010

\section{DOI: 10.1007/978-0-387-09484-7_9}

The publisher regrets that the section entitled "Practice 6: Being Open" was omitted from Chapter 8, "Practice Scripts and Descriptions." Please see the next page for the missing section. 


\section{Practice 6: Being Open}

Approximate timing: Introduction, 2 minutes; Practice, 10 minutes

A recording script that supports the "graduate level" mindfulness course Meeting Aggression, described in Chapter 6. Although certain language reflects the aggression/ non-aggression theme, the practice is useful in expanding the experience of embodiment, and makes a bridge, as well, to the teaching intention of moving towards acceptance.

\section{Introduction}

Suggesting that bodily posture or disposition reflects intellectual and emotional dispositions as well.

\section{Offering options for those who feel physically challenged.}

This meditation on being open is an opportunity to practice respect for our own experience - both inner and outer. When we do not like or do not approve of what is happening in the moment, there is often a tightening, a hardening, a freezing of opinion - we take a stand "against" what is arising. This is a physical, emotional, and intellectual expression of aggression, an example of "dis-respect." Respect, at the root, means, "to look again" - that is, to remain open, to assume a non-aggressive posture towards the experience in the moment. Such a posture will allow flexibility of response - to what is really required of us in the moment. You could say that it is about our capacity to be response-able.

Ideally, this practice is done standing. This CD track is just 10 minutes long, so that you will experience some physical challenge in remaining standing. Still, if you find the challenge too much, please feel free to do this practice in sitting posture, or to begin standing in front of your chair or cushion, and to take your seat when the time feels right to you - showing self-respect and being responsible to your own experience. 


\section{Practice}

Note: A simplified 10-posture Taijichuan form was taught in the course, so participants were familiar with this posture from seeing and participating. As with all practices, it is best for participants to learn in the presence of the teacher, and use the $C D$ track for support at home.

Encouraging observation, and offering freedom.

\section{Permissive option for eyes closed or open. \\ Touching emotion in the triangle of awareness.}

\section{Offering a greater perspective, an} expanding of awareness.
Beginning by taking a stand — not against anything, but IN your life in this moment. The commencing posture from Taijichuan is a model for a way of standing that reflects an open, flexible, respectful approach to your experience.

Feet together to start, arms at side; bring weight onto one leg, lift the opposite one, and step to the side so your feet are now under your hips — settled and balanced... ...And lifting arms out in front of you while bending the knees... and lowering the arms so the hands are extended in front of hips, palms down, fingers extended but relaxed... and simultaneously straightening the knees — until they are just slightly bent — and straightening the spine... feeling into uprightness... into standing....

Sensing into this posture, opening to the range of sensations in the body... ...willing to look again, to make any small or large adjustments required for ease and balance....

Eyes closed, if that's possible... sensing your feet on the floor... sensing any tightness in lower legs...knees... thigh muscles... hips and lower back... the spine rising up...

Shoulders open, chest open - perhaps there's a feeling of the heart opening, of some vulnerability to the imperfection and beauty, aggression and non-aggression of momentby-moment experience...

Sensing neck and head - spine rising up, chin tucked in, so the gaze is downward, whether eyes are open or closed...

Finding ease and openness in standing - aware of how this ease and openness offers infinite flexibility of response.... Aware of how this posture complements or conflicts with thoughts or emotions in this moment....

Open to the experience of yourself in the space of the environment.... Is it limited to what is in front of you? ... Our perceptual equipment faces forward, and we spend so much time leaning into the future and moving forward possibly even with aggression...

It may be the way we are built, with sense organs pointing forward, or it may be a habit, that you experience what is before you more often than other perspectives.... So, can you bring yourself into 360 degrees of connection with what surrounds you? Can you sense the space behind as well as before you — being open to it all — expanding your response-ability... the ability to respond...? 
Observing sound.

\section{Subtly adding the experience of seeing.}

\section{Permissive option for virtually any experience. \\ Observing the enormous scope of visual awareness.}

Permissive options.

\section{Offering options to end or extend practice.}

When you're ready, adding a focus on sounds to your experience ... allowing whatever sounds arise to come to you — without judgment or preference ... noticing that the sounds arise from all quarters - allowing them to help you remain open to the full 360 degree experience of standing.... (pause)

Noticing what closes you down... what shuts the valve of your experience — thought, emotion, body sensation...

As much as possible, working to reopen the valve when you find it closing; finding a way to respect your experience - to look again... (pause)

Now getting in touch with your eyes behind the eyelids... ...What are they doing?... ....Are they still?... ...Or are they trying to look?

Getting in touch with the eyelids, feeling their weight, maintaining contact with the sensation of their weight as you raise them....

Noticing that the visible world has entered your experience... opening to that... seeing new.... (Pause)

How does seeing affect posture?...... How does it affect breathing?... Being open, allowing whatever minute adjustments need to be made to stay open... to remain in a responsible, flexible posture in this moment.... (pause)

When it feels right to you, slowly raising your gaze... opening to the sense of the full environment - seeing or sensing peripherally the 360 degrees in which you stand...

Aware of moments of shutting down... aware of thoughts and feelings that arise that make openness difficult.... Accepting the struggle as your experience.... Showing respect by assuming responsibility for your own experience.... (Long pause)

As this standing meditation comes to an end, making a choice... to end your practice, or to continue with a sitting or lying-down meditation - maintaining the sense of openness, of respecting your experience, that you have been developing... (Bell) 